\title{
Penerapan Metode Job Safety Analysis and Risk Score untuk Meningkatkan Keselamatan dan Kesehatan Kerja pada Departemen Printing, Sewing dan Assembly PT. PAI, Bandung (Suatu Pendekatan Participatory Ergonomic)
}

\author{
Paulus Sukapto $^{1}$, Harjoto Djojosubroto ${ }^{2}$, Handy Permana ${ }^{3}$ \\ ${ }^{1,2,3}$ Program Studi Teknik Industri, Universitas Katolik Parahyangan Bandung, Indonesia \\ Email: paulus@unpar.ac.id
}

\begin{abstract}
Application of Job Safety Analysis and Risk Score Methods to Improve Occupational Safety and Health in the Printing, Sewing and Assembly Department of PT. PAI, Bandung (An Ergonomic Participatory Approach). The footwear industry problem lies in the working environment and facilities that do not meet the standards for the health and safety of workers, necessary improvements must be made. This research was used the questionnaire and observation to evaluate the activities of the work process. The EPPEQ questionnaire was used to evaluate the level of ergonomic participation in the activities examined. In addition the questionnaire, this research was also conducted observation in order to measure the risk level of the workplace and for improving the work system using PE (participatory ergonomics). The results showed that 3 workstations have high-risk levels, 4 stations have medium risk levels and 2 workstations have a low level of risk. The results of workers participation level using the EPPEQ ergonomics questionnaire showed that the level of ergonomic activity was fairly high, but based on the linear regression, the level of ergonomic activity does not differ in terms of the footwear workshop facilities, the work environment or the safety climate. Conclusion, there were 3 workstations with a high-risk score that should be immediately improved (the Glueing workstations, the Primering workstations, and the Leaching workstations). Specific improvements that need to be made are: First, for the Glueing workstation they include the use of APD and the addition of an air suction device, for the Primering workstation the use of APD and a Gleco Trap for liquid storage; Second, for the Laundering workstation the use of APD, and for the Emboss workstation the improvement consists of making additional buttons.
\end{abstract}

Keywords: Job Safety Analysis (JSA), Participatory ergonomics, Risk score, Safety climate

\begin{abstract}
Abstrak: Penerapan Metode Job Safety Analysis and Risk Score untuk Meningkatkan Keselamatan dan Kesehatan Kerja pada Departemen Printing, Sewing dan Assembly PT. PAI, Bandung (Suatu Pendekatan Participatory Ergonomic). Masalah dalam industri sepatu adalah fasilitas dan lingkungan kerja belum memenuhi standar kesehatan dan keselamatan pekerja sehingga perlu dilakukan perbaikan. Instrumen penelitian kuesioner dan observasi untuk mengevaluasi kegiatan proses kerja. Kuesioner EPPEQ digunakan untuk mengevaluasi tingkat aktivitas ergonomi partisipasi. Selain menyebarkan kuesioner, penelitian juga melakukan observasi untuk pengukuran tingkat risiko tempat kerja dan melakukan perbaikan sistem kerja dengan menggunakan PE (participatory ergonomics). Hasil perhitungan 3 stasiun kerja yang mempunyai tingkat risiko tinggi, 4 stasiun mempunyai tingkat risiko sedang dan 2 stasiun kerja mempunyai tingkat risiko rendah. Hasil perhitungan tingkat ergonomi partisipasi pekerja menggunakan kuesioner EPPEQ menunjukkan aktivitas ergonomi yang cukup bagus, namun berdasarkan regresi linear tingkat aktivitas ergonomi tidak berbeda terhadap fasilitas workshop sepatu dan lingkungan kerja serta iklim keselamatan kerja. Disimpulkan bahwa ada 3 stasiun kerja yang memiliki risk scoretinggi sehingga harus segera diperbaiki adalah Stasiun Kerja Pengeleman, Stasiun Kerja Primering, dan Stasiun Kerja Pencucian. Perbaikan yang perlu dilakukan adalah: pertama, di Stasiun Kerja Pengeleman berupa penggunaan APD dan penambahan penghisapudara, Stasiun Kerja Primering berupa penggunaan APD dan alat bantu penyimpan cairan gleco primer karet; kedua, di Stasiun Kerja Pencucian berupa penggunaan APD, dan Stasiun Emboss berupa membuat tombol tambahan.
\end{abstract}

Kata kunci: Job Safety Analysis (JSA), Participatory ergonomics, Risk score, Iklim keselamatan 
Di Indonesia salah satu perusahaan yang bergerak di industri sepatu adalah PT Primarindo Asia Infrastruktur Tbk yang mempunyai jumlah karyawan lebih dari 100 orang.

Hasil penelitian Sukapto dan Bonita (2016) menunjukan bahwa jumlah rata-rata kecelakaan tiap tahun di perusahaan ini adalah 20 kali. Menurut Reason (2000) terdapat 2 macam pendekatan untuk melihat kesalahan yang dilakukan oleh manusia yaitu, pendekatan orang (person approach) dan pendekatan sistem (system approach). Pendekatan sistem memiliki sifat proaktif untuk menangani potensi bahaya. Saat ini usulan perbaikan dengan pendekatan orang sudah tidak efektif lagi untuk digunakan. Usulan perbaikan dengan pendekatan sistem lebih efektif daripada usulan perbaikan dengan pendekatan orang (Sukapto dan Djojosubroto, 2013).

Penelitian ini berfokus pada Sistem Manajemen Keselamatan dan Kesehatan Kerja (SMK3). Penerapan SMK3 mengenai pencegahan dalam kecelakaan kerja akan melibatkan beberapa pihak seperti manajemen dan pekerja secara terintegrasi (Sukapto dan Djojosubroto, 2013). Untuk meningkatkan kinerja SMK3 dapat digunakan pendekatan participatory ergonomics (PE). Dengan digunakannya pendekatan PE maka dapat terbentuk sebuah tim manajemen Keselamatan dan Kesehatan Kerja (K3) yang mampu membuat sistem kerja yang aman dan nyaman bagi pekerja.

Pada pendekatan PE, aspek ergonomics merupakan hal yang penting. Menurut Shah dan Silverstein (2010), ergonomics adalah sebuah ilmu untuk merancang sebuah pekerjaan atau tempat kerja yang sesuai dengan kemampuan dan keterbatasan dari tubuh manusia. Ergonomics bertujuan untuk meningkatkan efisiensi, produktivitas, kenyamanan, dan keselamatan dari pekerja dan untuk menurunkan kesalahan, kecelakaan, luka dan penyakit (Boyce, M.R., 2008). Ergonomics dapat menjadi strategi kualitas dari suatu perusahaan karena berkontribusi terhadap quality performance (Erdinc \& Yeow, 2011). Agar supaya penerapan ergonomics berjalan dengan baik, maka dibutuhkan lingkungan yang kondusif sehingga interaksi pekerja dengan lingkungan sekitarnya dapat berjalan dengan baik (Dianat et al, 2016). Menurut Skrehot, Marek, dan Houser (2016) aspek ergonomics akan dipertimbangkan saat proses pengembangan sistem kerja yang baru atau untuk memperbaiki lingkungan kerja yang sudah dipakai sehingga semua masalah dan defisiensi dari sistem sekarang dapat ditemukan.
Secara keseluruhan pendekatan PE adalah sebuah pendekatan yang secara aktif terdiri dari individu yang memiliki pengetahuan luas dan bertanggung jawab. Secara khusus, efek positif dari partisipasi pekerja telah ditunjukan dari banyak penelitian (Larson et al, 2015). Penerapan PE dengan mengumpulkan sekelompok desainer, bagian produksi dan peneliti tentang ergonomics. Kelompok ini akan menggunakan berbagai metode untuk meningkatkan desain produk (Sundin et al, 2004). Tahapan PE terdiri persiapan, analisis kerja dan kesehatan, pemilihan perbaikan, perbaikan dengan Pilot-study, dan implementasi (De Jong \& Vink, 2000). Tujuannya untuk mengurangi paparan risiko keselamatan di tempat kerja dengan cara merancang ulang proses dan alat-alat kerja (Tompa et al, 2009). Proses PE yang baik adalah agar solusi yang dihasilkan dapat disepakati oleh setiap pihak dengan cara musyawarah (Punett et al., 2013).

Tim yang sudah terbentuk ini akan mencari solusi bersama-sama dengan cara musyawarah mengenai potensi bahaya yang ditemukan. Menurut Azadeh, Roudi, dan Salehi (2017) masalah-masalah yang terkait dengan keselamatan dapat diperbaiki dengan meningkatkan komunikasi antara pekerja dan manajer. Menurut Kumar, Chaikumarn, dan Lundberg (2005), PE adalah sebuah metode yang pengguna akhir berperan aktif di dalam mengidentifikasi, menganalisis faktor-faktor risiko dan dalam mendesain serta menerapkan solusinya dari aspek ergonomi.

Menurut pakar ergonomi makro Nagamachi, M. (1995), PE adalah keterlibatan daripekerja-pekerja dalam mengimplementasikan pengetahuan tentang ergonomi dan prosedur dalam tempat kerja pekerja tersebut. Ditambahkan, menurut Motamedzade (2013), PE didefinisikan sebagai keterlibatan pekerja-pekerja dalam merencanakan dan mengkontrol aktivitas kerjanya dengan pengetahuan dan tenaga yang cukup untuk mempengaruhi proses dan hasil yang sesuai dengan tujuan yang diinginkan (Motamedzade, 2013; Wang dan Lau 2012; Santos et al, 2011; Saleem et al, 2003).

Oleh karena itu pendekatan PE digunakan untuk mencari solusi dari masalah-masalah yang terdapat dalam PT Primarindo Asia Infrastruktur Tbk. Hal ini bertujuan agar potensi bahaya dan kecelakaan kerja pada perusahaan dapat berkurang, pekerjaan yang dilakukan lebih aman dan nyaman, dan lebih efisien serta SMK3 dalam PT Primarindo Asia Infrastruktur Tbk dapat meningkat. 


\section{METODE}

Metode yang digunakan dalam penelitian ini adalah dengan menggunakan kuesioner dan observasi. Kedua metode tersebut untuk mengukur iklim keselamatan kerja.

Tahapan penelitian terbagi menjadi 4 tahap, yaitu pembuatan JSA, perhitungan RS, proses PE, dan perbaikan sistem kerja.

\section{Job Safety Analysis}

Job Safety Analysis (JSA) atau dapat disebut juga sebagai Job Hazard Analysis (JHA) merupakan sebuah proses dimana langkahlangkah kerja dalam suatu pekerjaan dianalisis dan diurutkan dalam sebuah daftar. Setiap langkah tersebut dianalisis untuk mengidentifikasi potensi bahaya yang ada di dalamnya. Bahaya yang dimaksud adalah kondisi atau aktifitas yang dapat mengakibatkan cedera atau penyakit jika tidak terkendali dengan baik.

JSA dapat didefinisikan sebagai teknik yang berfokus pada tugas-tugas dalam pekerjaan untuk mengidentifikasi bahaya sebelum bahaya tersebut terjadi. Teknik ini berfokus pada hubungan antara pekerja, pekerjaannya, peralatan yang digunakan, dan lingkungan kerja. Setelah bahaya teridentifikasi, biasanya teknik ini akan dilanjutkan dengan langkah perbaikan untuk mengurangi atau menghilangkan bahaya agar bahaya berada dalam batasan yang dapat dikendalikan (OSHA3071, 2002). Agar penggunaan JSA dapat efektif, pihak manajemen harus dapat menunjukan komitmennya terhadap keselamatan dan kesehatan kerja dengan menindak-lanjuti bahaya yang teridentifikasi. Jika tidak, pihak manajemen dapat kehilangan kepercayaan dari pekerja karena pekerja akan merasa ragu pada pihak manajemen ketika mengalami suatu kondisi yang mengancam keselamatan dan kesehatan pekerja selama bekerja.

Tahapan dalam analisis yang diperlukan dalam melakukan JSA menurut Goetsch, (2017) diantaranya menentukan jenis pekerjaan yang akan dianalisis, menjabarkan pekerjaan menjadi langkah-langkah kerja, meneliti dan menentukan bahaya yang mungkin terjadi pada setiap langkah kerja, kemudian menentukan tindakan pencegahan yang dapat dilakukan dari setiap bahaya. Biasanya JSA dibuat dalam bentuk tabel. Berikut adalah contoh analisis potensi bahaya dengan menggunakan JSA pada Metal Shop dalam Gambar 1 (OSHA3071, 2002).

\section{Job Location: \\ Metal Shop \\ Analyst: \\ Date:}

Task Description : Worker reaches into metal box to the right of the machine, grasps a 15-pound casting and carries it to grinding wheel. Worker grinds 20 to 30 castings per hour.

Hazard Description: Picking up a casting, the employee could drop it onto his foot. The casting's weight and height could seriously injure the worker's foot or toes.

\section{Hazard Controls:}

1. Remove castings from the box and place them on a table next to the grinder.

2. Wear steel-toe shoes with arch protection.

3. Change protective gloves that allow a better grip.

4. Use a device to pick up castings.

\section{Gambar 1. Job Safety Analysis Form}

Berdasarkan Gambar 1 tersebut, tabel yang selanjutnya akan digunakan dalam penelitian adalah seperti pada Gambar 2.

\begin{tabular}{|l|l|l|l|l|}
\hline \multicolumn{3}{|c|}{ Lembar JSA di Stasiun Emboss } & Tindakan \\
\cline { 1 - 3 } No & $\begin{array}{l}\text { Langkah } \\
\text { Kerja }\end{array}$ & $\begin{array}{l}\text { Potensi } \\
\text { Bahaya }\end{array}$ & Effect & Korektif \\
\hline 1 & $\begin{array}{l}\text { Meletakan } \\
\text { material } \\
\text { sepatu ke } \\
\text { meja kerja } \\
\text { mesin }\end{array}$ & $\begin{array}{l}\text { Panas } \\
\text { yang } \\
\text { dihasilkan } \\
\text { dari metal } \\
\text { yang ada } \\
\text { di mesin }\end{array}$ & $\begin{array}{l}\text { Membuat } \\
\text { tombol } \\
\text { tambahan } \\
\text { untuk } \\
\text { pengaman }\end{array}$ & $\begin{array}{l}\text { Meletakan } \\
\text { material } \\
\text { sepatu ke } \\
\text { meja kerja } \\
\text { mesin }\end{array}$ \\
\hline \multirow{2}{*}{2} & $\begin{array}{l}\text { Melakukan } \\
\text { proses } \\
\text { emboss, }\end{array}$ & $\begin{array}{l}\text { Panas } \\
\text { yang } \\
\text { dihasilkan } \\
\text { dari metal } \\
\text { yang ada } \\
\text { di mesin }\end{array}$ & $\begin{array}{l}\text { Membuat } \\
\text { tombol } \\
\text { tambahan } \\
\text { untuk } \\
\text { pengaman }\end{array}$ & $\begin{array}{l}\text { Melakukan } \\
\text { proses } \\
\text { emboss, }\end{array}$ \\
\hline
\end{tabular}

Gambar 2. Lembar Job Safety Analysis yang Digunakan

\section{Risk Score}

Menurut Goetsch (2017), definisi hazard adalah suatu hal yang memiliki potensi untuk menimbulkan kerusakan alat, mesin, ataupun organisasi. Selain kerusakan, hazard berpotensi untuk menjadi insiden yang berakibat pada kerugian. Risiko merupakan konsekuensi dari suatu kejadian yang berbahaya atau kerusakan yang timbul akibat bahaya yang ada. Pada perhitungan risk score, dilakukan pemberian nilai kuantitatif terhadap bahaya yang ada pada suatu pekerjaan dan dampak yang diakibatkan dari bahaya tersebut. Perhitungan risk score dapat dilakukan sebelum atau setelah kecelakaan terjadi.

Risk score (RS) dihitung dengan menggunakan Persamaan 1 berdasarkan rating dari ketiga faktor kecelakaan, yaitu 
consecuencies $(C)$, exposure $(E)$, dan probabilty $(P)$ dari suatu kecelakaan kerja (Fine,1971).

$$
\mathrm{RS}=\mathrm{C} \times \mathrm{E} \times \mathrm{P}(\text { Pers }-1)
$$

Informasi tentang nilai $\mathrm{C}, \mathrm{E}$, dan $\mathrm{P}$ dapat dilihat dalam Lampiran 1.

\section{Pengukuran Tingkat Aktivitas PE}

Menurut Matthews et al., (2011) tingkat aktivitas PE dilakukan menggunakan Employee Perceptions of Participatory Ergonomics Questionnaire (EPPEQ). Kuesioner ini terdiri dari 17 pernyataan yang terbagi ke dalam 5 dimensi. Kelima dimensi dari ergonomi partisipasi antara lain keterlibatan diri, pengetahuan ergonomi, dukungan manajer, dukungan dari karyawan dan kendala. Skala yang digunakan pada kuesioner adalah 1 hingga 4 . Skala 1 (sangat tidak setuju) skala 4 (sangat setuju).

\section{Implementasi PE}

Implementasi PE melibatkan tiga unsur utama yaitu manajemen, pekerja dan ahli K3. Ketiga unsur ini secera terus menerus melakukan diskusi untuk mendapatkan kesepakatan bersama. Hasil kesepakatan adalah dalam bentuk konsep desain yang tentunya akan berguna bagi perusahaan yaitu meningkatkan produktivitas kerja dan tentunya menurunkan kecelakaan kerja.

\section{Perbaikan Stasiun Kerja}

Perbaikan sistem kerja mengacu pada nilai RS. Untuk nilai RS yang diatas 300 maka harus segera dilakukan perbaikan. Nilai 200 sampai dengan 300 menjadi prioritas kedua dalam melakukan perbaikan.

\section{HASIL}

\section{Pembagian Stasiun Kerja}

Departemen Printing, Sewing, dan Assembly terbagi menjadi 9 (sembilan) stasiun kerja. Pembagian stasiun kerja dapat dilihat pada Tabel 1.
Tabel 1. Nama Stasiun Kerja

\begin{tabular}{ll}
\hline No & Stasiun Kerja \\
\hline 1 & Emboss \\
2 & Mesin sablon \\
3 & Memanaskan sablon \\
4 & Pounching \\
5 & Kancing \\
6 & Pengelaman \\
7 & Primering \\
8 & Pencucian \\
9 & Universal \\
\hline
\end{tabular}

\section{Pembuatan Job Safety Analysis (JSA)}

Masing-masing stasiun kerja yang terdapat pada Tabel 1 akan dibuatkan JSA. Berikut contoh ini analisis dengan menggunakan JSA pada Stasiun Kerja Emboss dapat dilihat pada Tabel 2.

\begin{tabular}{|c|c|c|}
\hline \multicolumn{3}{|l|}{ JOB SAFETY ANALYSIS } \\
\hline $\begin{array}{l}\text { Division : Production, } \\
\text { Departemen printing }\end{array}$ & $\begin{array}{l}\text { Machine/O } \\
\text { Emboss } m a\end{array}$ & $\begin{array}{l}\text { eration } \\
\text { hine }\end{array}$ \\
\hline Task Steps & $\begin{array}{l}\text { Potential } \\
\text { Hazards }\end{array}$ & $\begin{array}{l}\text { Safety } \\
\text { Control }\end{array}$ \\
\hline $\begin{array}{l}\text { 1. Menyalakan mesin } \\
\text { emboss }\end{array}$ & & \\
\hline $\begin{array}{l}\text { 2. Meletakan material } \\
\text { sepatu ke meja kerja } \\
\text { mesin }\end{array}$ & $\begin{array}{l}\text { Panas } \\
\text { yang } \\
\text { dihasilkan } \\
\text { dari metal } \\
\text { yang ada } \\
\text { di mesin } \\
\end{array}$ & $\begin{array}{l}\text { Membuat } \\
\text { tombol } \\
\text { tambahan } \\
\text { untuk } \\
\text { pengaman }\end{array}$ \\
\hline $\begin{array}{l}\text { 3. Melakukan } \\
\text { emboss }\end{array}$ & $\begin{array}{l}\text { Panas } \\
\text { yang } \\
\text { dihasilkan } \\
\text { dari metal } \\
\text { yang ada } \\
\text { di mesin } \\
\end{array}$ & $\begin{array}{l}\text { Membuat } \\
\text { tombol } \\
\text { tambahan } \\
\text { untuk } \\
\text { pengaman }\end{array}$ \\
\hline $\begin{array}{l}\text { 4. Mengeluarkan material } \\
\text { sepatu yang telah di } \\
\text { emboss }\end{array}$ & $\begin{array}{l}\text { Panas } \\
\text { yang } \\
\text { dihasilkan } \\
\text { dari metal } \\
\text { yang ada } \\
\text { di mesin } \\
\end{array}$ & $\begin{array}{l}\text { Membuat } \\
\text { tombol } \\
\text { tambahan } \\
\text { untuk } \\
\text { pengaman }\end{array}$ \\
\hline
\end{tabular}

\section{Pengukuran Tingkat Risiko}

Pengukuran tingkat risiko masing-masing stasiun kerja menggunakan metode Willian Fine. Pengukuran tingkat risiko dengan menggunakan rumus $\mathrm{RS}=\mathrm{CxExP}$, dimana consequences $(\mathrm{C})$, exposure (E), dan probability (P). Setelah ditentukan nilai $\mathrm{C}, \mathrm{E}$, dan $\mathrm{P}$, perhitungan risk score dapat dilakukan. Contoh perhitungan risk score untuk Stasiun Kerja Emboss adalah seperti berikut: Risk Score $(\mathrm{R})=5 * 3 * 6=90$ 
Hasil perhitungan Risk score untuk delapan stasiun kerja lainnya dapat dilihat pada Tabel 3.

Tabel 3. Hasil Pengukuran RS sesuai dengan Tingkat Risiko masing-
masingStasiun Keria

\begin{tabular}{clc} 
Prioritas & Stasiun Kerja & RS \\
\hline 1 & Pengeleman & 300 \\
1 & Primering & 300 \\
1 & Pencucian & 300 \\
2 & Sablon & 180 \\
2 & Universal & 150 \\
2 & Memanaskan sablon & 135 \\
2 & Emboss & 200 \\
2 & Pounching & 90 \\
2 & Kancing & 90
\end{tabular}

Catatan: Nilai RS sebesar200-300 adalah kategori tingkat risiko tinggi, RS sebesar 90-299 adalah kategori tingkat risiko sedang, dan Nilai RS di bawah 90 adalah kategori tingkat risiko rendah.

\section{Perbaikan Sistem Kerja}

\section{a. Pengukuran Tingkat Aktivitas PE}

PE merupakan suatu metode yang masih relatif baru digunakan untuk melakukan perbaikan. Penerapan metode ini adalah diskusi secara intensif pihak pekerja, manajemen dan ahli ergonomi/ahli K3. Sebelum proses PE dilakukan secara sungguh-sungguh maka terlebih dahulu diukur tingkat partisipasinya dengan menggunakan EPPEQ.

Penyebaran kuesioner akan dilakukan pada pekerja dalam Departemen Printing, Sewing, dan Assembly. Hasil kuesioner EPPEQ yang didapat adalah sebanyak 93 buah. Aktivitas ergonomi pekerja dianalisis menggunakan kuesioner EPPEQ yang terdiri dari 5 dimensi yang terbagi dalam 17 pernyataan. Kelima dimensi dari ergonomi partisipasi antara lain keterlibatan diri, pengetahuan ergonomi, dukungan manajer, dukungan dari karyawan dan kendala. Skala yang digunakan pada kuesioner adalah 1 hingga 4 . Skala 1 (sangat tidak setuju) dan skala 4 (sangat setuju). Akan tetapi sebaliknya pada penilaian Dimensi Kendala skala 1 (sangat setuju) dan skala 4 (tidak setuju). Nilai rata-rata pernyataan 1 hingga 17 sudah bernilai lebih besar dari 3 . Pernyataan nomor 2, 8, 15 dan 16 masih memiliki nilai dibawah 3. Pernyataan ini termasuk ke dalam dimensi kendala dengan penilaian terbalik, sehingga dapat dikategorikan sudah baik. Secara umum menunjukkan aktivitas ergonomi partisipasi pekerja sudah cukup bagus yaitu nilai rata-rata EPPEQ adalah 3,27. Sementara itu, aktivitas ergonomi tersebut tidak berbeda bermakna terhadap fasilitas pada
Departemen Printing, Sewing,dan Assemblydan lingkungan kerja serta iklim keselamatan kerja $(\mathrm{p}>0,05)$.

\section{b. Penerapan PE}

Setelah pengukuran tingkat aktivitas PE dinyatakan baik, maka langkah selanjutnya adalah melakukan proses PE. Proses ini dilakukan pada tempat/stasiun kerja yang akan diperbaiki. Masing-masing stasiun dilakukan diskusi secara konsisten dan akhirnya mendapat kesepakan bersama. Masing-masing stasiun kerja membutuhkan waktu diskusi rapat 4 kali diskusi. Berikut contoh proses penerapan PE dapat dilihat pada Stasiun Kerja Pengeleman, Primering, dan Pencucian serta Stasiun Emboss dapat dilihat pada Subbab 4.d.

\section{c. Diskusi pada Stasiun Kerja Pengeleman, Primering dan Pencucian}

Proses yang dilakukan pada Stasiun Kerja Pengeleman, Primering, dan Pencucian yaitu mengoleskan cairan kimia (yaitu Aseton) pada bagian-bagian sepatu. Cairan-cairan kimia ini dapat menyebabkan terganggunya kesehatan pekerja, apabila pekerja menghirup bau dalam waktu tertentu. Apabila cairan ini mengenai kulit pekerja maka kulit akan mengalami iritasi dan lama-kelamaan kulit akan mengalami kerusakan kulit. Pendekatan PE dilakukan dengan cara berdiskusi secara intensif oleh pihak manajemen, pekerja dan ahli K3 dengan tujuan untuk mendapatkan suatu perbaikan yang akan memberikan keuntungan secara bersama-sama terutama dalam bidang keselamatan dan kenyamanan pekerja (Santos et al., 2011; Wilkinson dan Agnelli, 2014; Azadeh et al., 2017). Penerapan PE dengan cara berdiskusi pihak manajemen, pekerja dan ahli K3 dapat dilihat pada Gambar 3 dan Gambar 4.

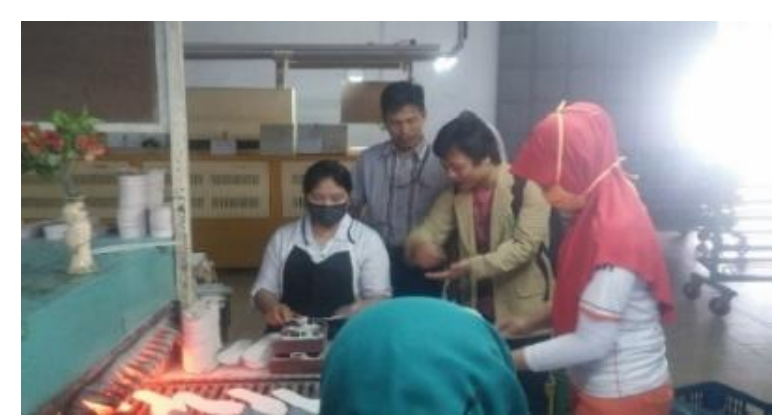

Gambar 3. Penerapan PE di Stasiun Kerja Pengeleman 


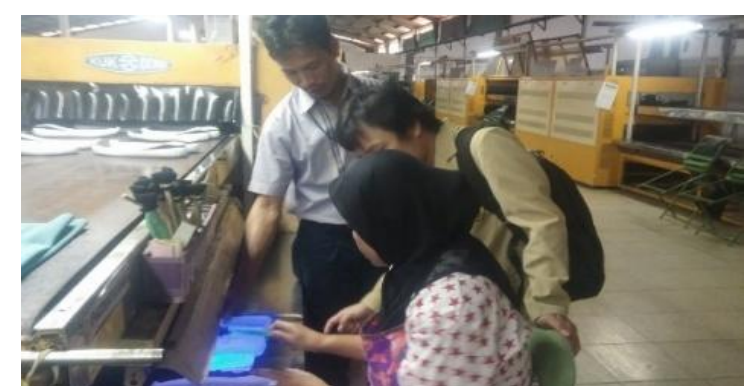

Gambar 4. Penerapan PE di Stasiun Kerja Primering

Hasil diskusi yang dilakukan secara konsisten akhirnya mendapatkan kesepakatan sebagai berikut: pertama, pekerja selalu menggunakan masker saat bekerja. Dengan menggunakan masker maka mereka akan mampu bekerja dengan nyaman karena mengurangi aroma bau menyengat dari bahan kimia yang digunakan. Kedua, perlu pemasangan exhaust fanyang mampu menyedot bau-bau dari cairan kimia terhisap keluar dari ruangan. Dengan adanya solusi perbaikan ini lingkungan kerja dapat lebih baik sehingga produktivitas kerja, kenyamanan, dan kesehatan kerja dapat meningkat (Dianat et al., 2016). Ketiga, yaitu menyediakan alat bantu untuk menyimpanbahan kimia yang digunakan (Santos et al, 2011; Tompa et al, 2009).

\section{d. Diskusi Pada Stasiun Kerja Emboss}

Potensi bahaya di Stasiun Kerja emboss adalah metal panas dari mesin mengenai tangan pekerja. Diskusi yang dilakukan pada stasiun kerja iniadalah mencari perbaikan pada sistem kerja. Informasi proses diskusi dapat dilihat pada Gambar 5 dan Gambar 6.

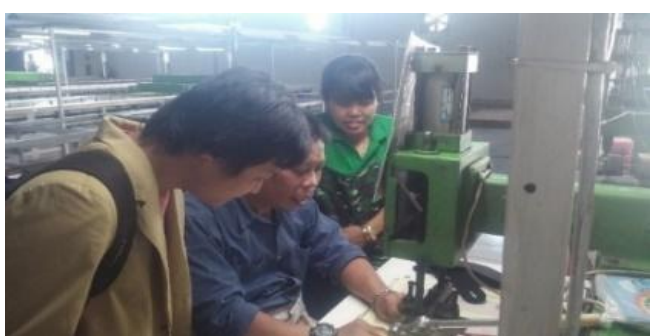

Gambar 5. Diskusi Pada Stasiun Kerja Emboss

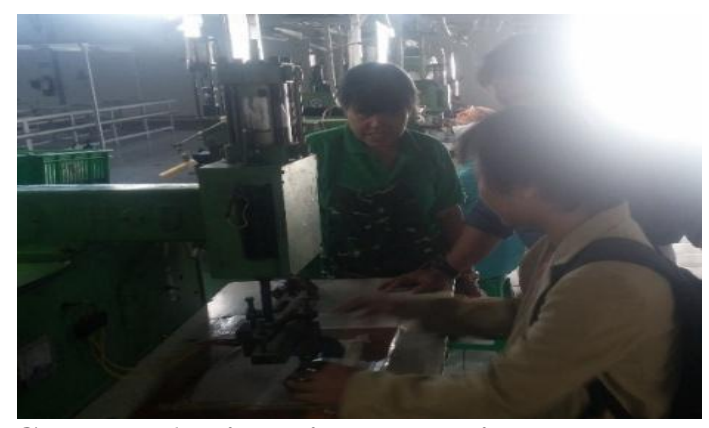

\section{Gambar 6. Diskusi Mengenai Usulan pada} Stasiun Kerja Emboss

Penerapan PE dengan cara berdiskusi yang dilakukan pada Stasiun Kerja Primeringdan Stasiun Kerja Emboss. Proses diterapkan juga pada tujuh stasiun kerja lainnya. Hasil kesepakatan yang diperoleh dari tiga unsur utama yaitu pihak manajemen, karyawan dan ahli ergonomi dapat dilihat pada Tabel 4.

\section{Tabel 4. Hasil Kesepakatan Perbaikan}

\begin{tabular}{|c|c|c|}
\hline No & Stasiun Kerja & Hasil Kesepakatan Perbaikan \\
\hline \multirow{3}{*}{1} & \multirow{3}{*}{ Pengeleman } & Wajib mengenakan APD (masker) \\
\hline & & $\begin{array}{l}\text { Menambahkan fasilitas untuk } \\
\text { menghisap udara dalam ruangan } \\
(\text { exhaust fan) }\end{array}$ \\
\hline & & $\begin{array}{l}\text { Menambahkan alat bantu untuk } \\
\text { menyimpan cairan lateks }\end{array}$ \\
\hline \multirow{3}{*}{2} & \multirow{3}{*}{ Primering } & Wajib mengenakan APD (masker) \\
\hline & & $\begin{array}{l}\text { Menambahkan fasilitas } \text { untuk } \\
\text { menghisap udara dalam ruangan } \\
\text { (exhaust fan) }\end{array}$ \\
\hline & & $\begin{array}{l}\text { Menambahkan alat bantu untuk } \\
\text { menyimpan cairan gleco primer } \\
\text { karet } 001 \mathrm{KA}\end{array}$ \\
\hline \multirow{3}{*}{3} & \multirow{3}{*}{ Pencucian } & Wajib mengenakan APD (masker) \\
\hline & & $\begin{array}{l}\text { Menambahkan fasilitas untuk } \\
\text { menghisap udara dalam ruangan } \\
\text { (exhaust fan) }\end{array}$ \\
\hline & & $\begin{array}{l}\text { Menambahkan alat bantu untuk } \\
\text { menyimpan cairan MEK }\end{array}$ \\
\hline \multirow{3}{*}{4} & \multirow{3}{*}{ Sablon } & Wajib mengenakan APD (masker) \\
\hline & & $\begin{array}{l}\text { Menambahkan fasilitas untuk } \\
\text { menghisap udara dalam ruangan } \\
\text { (exhaustfan) }\end{array}$ \\
\hline & & Memodifikasi alat kerja sablon \\
\hline 5 & Universal & $\begin{array}{l}\text { Membuat tombol tambahan untuk } \\
\text { pengaman }\end{array}$ \\
\hline 6 & $\begin{array}{l}\text { Memanaskan } \\
\text { Sablon }\end{array}$ & $\begin{array}{l}\text { Menginstalasi kabel mesin pada } \\
\text { sebuah cable winder }\end{array}$ \\
\hline 7 & Emboss & $\begin{array}{l}\text { Membuat tombol tambahan untuk } \\
\text { pengaman }\end{array}$ \\
\hline \multirow[b]{2}{*}{8} & \multirow[b]{2}{*}{ Pounching } & $\begin{array}{l}\text { Memodifikasi mesin, alat bantu } \\
\text { dibuat menempel dengan mesin }\end{array}$ \\
\hline & & $\begin{array}{l}\text { Memodifikasi mesin, dengan cara } \\
\text { menambahkan penghalang pada } \\
\text { bagian press mesin }\end{array}$ \\
\hline 9 & Kancing & $\begin{array}{l}\text { Membuat } 1 \text { tombol tambahan untuk } \\
\text { menggantikan fungsi pedal }\end{array}$ \\
\hline
\end{tabular}

Hasil kesepakatan tentang konsep perbaikan akan menjadi acuan bagi perusahaan pada saat melakukan perbaikan. Proses perbaikan 
dalam penelitian ini hanya mengacu pada nilai risiko yang membutuhkan perbaikan secepatnya yaitu yang memiliki nilai RS sebesar 200-300.

\section{PEMBAHASAN}

Menurut Sukapto (2013) dan Tompa (2009), proses perbaikan sistem kerja dengan menggunakan PE merupakan suatu cara yang akan menguntungkan semua pihak karena telah disepakati bersama. Karyawan mempunyai peran yang penting sekali karena mereka mengetahui karakteristik pekerjaan tersebut. Karyawan akan memberikan masukan yang berarti sehingga proses perbaikan akan menjadi lebih baik dari kondisi pekerjaan saat ini. Peran manajemen juga penting karena mereka yang mempunyai wewenang terhadap masing-masing pekerjaan. Wewenang yang dimaksud adalah pengaturan alokasi sumberdaya untuk masing-masing stasiun kerja. Selain itu, pihak manajemen mempunyai peran dalam menentukan target produksi pada masing-masing stasiun kerja. Peran ahli K3 menjadi mediator dan pengarah bagi pihak pekerja dan manajemen agar konsep desain yang dibuat sesuai dengan harapan pihak karyawan dan pihak manajemen. Metode ini sangat cocok untuk digunakan di perusahaan ini karena sejalan dengan budaya perusahaan yang ada saat ini yaitu musyawarah dan mufakat. Budaya ini telah menjadi suatu tradisi turun temurun di perusahaan ini.

Ditambahkan pula oleh Van Eerd (2010) bahwa partisipasi ergonomi adalah keterlibatan aktif dari pekerja dalam melakukan implementasi pengetahuan dan prosedur ergonomi di tempat kerja yang didukung oleh manajer dan juga supervisor. Dalam penerapannya pada penelitian ini, langkah pertama yang dilakukan adalah mengenalkan ergonomi dan ergonomi partisipasi pada pekerja serta pimpinan perusahaan dengan harapan pekerja dan pimpinan perusahaan mempunyai pengetahuan terkait ergonomi partisipasi sehingga memudahnya dalam menganalisis hubungan antara partisipasi ergonomi terhadap lingkungan dan fasilitas perusahaan serta hubungannya dengan keselamatan kerja. Dalam kaitan ini peranan sosial pekerja dan pemilik organisasi menjadi substansi penting untuk mendukung pengawasan kesehatan dan keselamatan pekerja (Giovanni, 2010).

Hasil penelitian ini menunjukkan aktivitas partisipasi ergonomi memiliki nilai baik. Evaluasi partisipasi ergonomi bertujuan untuk mengidentifikasi bagian dari program evaluasi yang membutuhkan perbaikan untuk segera diperbaiki (Matthews, 2011). Hal ini memberikan informasi bahwa aktivitas partisipasi ergonomi muncul dari kesadaran pekerja sendiri untuk selalu waspada dalam berbagai tindakan kerja meskipun pemilik tidak memfasilitasinya. Kendati demikian diperlukan unsur intervensi profesional dalam bidang ergonomi untuk menyeimbangkan antara aktivitas ergonomis dengan kelelamatan kerja, faslitas pendukung tempat kerja dan lingkungan sekitarnya (Boatca, 2015).

Penerapan PE pada Stasiun Kerja Pengeleman, Primering dan Pencucian yang penting adalah memastikan semua karyawan paham sekali bahwa adanya dampak jangka panjang yang diakibatkan apabila karyawan secara terus menerus menghirup bahan kimia yang digunakan dalam proses produksi. Dalam penelitian ini juga dilakukan evaluasi bahan kimia seperti benzene, toluene, xylene yang sering digunakan pada pembuatan sepatu. Ketiga bahan tersebut merupakan pelarut organik yang terkandung pada komposisi lem dan dapat berdampak buruk bagi kesehatan manusia diantaranya kerusakan sistem saraf, kulit, liver, ginjal, sistem kekebalan dan paru-paru, kemudian bahan kimia juga bersifat mudah terbakar sehingga dapat menyebabkan kebakaran (Markkanen, 2004). Pada pekerja cenderung membersihkan lem dengan bensin atau minyak tanah yang membuat semakin menambah paparan benzene dan toluene yang masuk ke dalam tubuh (Lim, 2014). Dari hasil kesepakatan dengan pihak pekerja, pihak perusahaan akan menyediakan masker secara gratis dan pekerja akan menggunakannya dengan penuh kesadaran. Selain itu, pihak pekerja akan tetap menjaga agar lingkungan kerja tetap dalam kondisi yang bersih sehingga kemungkinan terjadi kebakaran tidak akan terjadi. Dengan kesepakatan ini maka akan muncul suasana kerja yang aman dan sehat bagi pekerja (Santos et al, 2011 ).

Penerapan PE di Stasiun Embos adalah memastikan bahwa pekerja paham dalam menjalankan mesin dengan sempurna. Dalam pengamatan selama penelitian, pekerja sering ceroboh dalam menjalankan mesin sehingga tangan terjepit dalam mesin tersebut sehingga terjadi cacat bagian jari tangan karyawan. Hasil kesepakatan adalah dalam mesin ini ditambahkan tombol satu lagi sehingga dalam menjalankan aktivitas ini harus menekan kedua tombol secara bersamaan. Hasil modifikasi ini maka tidak akan terjadi kecelakaan karena kedua tangan menekan tombol secara bersamaan. Dengan modifikasi ini 
maka diwujudkan suasana kerja yang aman bagi karyawan (Saleem, 2003).

\section{SIMPULAN}

Tiga stasiun kerja yang memiliki risk score tinggi sehingga harus segera diperbaiki adalah Stasiun Kerja Pengeleman, Stasiun Kerja Primering, dan Stasiun Kerja Pencucian. Perbaikan yang perlu dilakukan adalah: pertama, di Stasiun Kerja Pengeleman berupa penggunaan APD dan penambahan penghisap udara, Stasiun Kerja Primeringberupa penggunaan APD dan

\section{DAFTAR PUSTAKA}

Azadeh, A., Roudi, E., dan Salehi, V. 2017. Optimum Design Approach Based on Integrated Macro-ergonomics and Resilience Engineering in a Tile and Ceramic Factory,96, 62-74. doi:10.1016/j.ssci/2017.02.017

Boatca ME, Cirjaliu B. 2015. A proposed approach for an efficient ergonomics intervention in organizations. Procedia Econ Financ, 23:54-62.

Boyce, M.R. 2008. An Ergonomic Approach to the Aging Workforce Utilizing This Valuable Resource to Best Advantage by Integrating Ergonomics, Health Promotion and Employee Assistance Programs,23, 179-199. doi:10.1080/15555240802189588

De Jong, A.M., dan Vink, P. 2000. The Adoption of Technological Innovations for Glaziers Evaluation of a Participatory Ergonomics Approach, 26, 39-46.

Dianat, I., Vahedi, A., \& Dehnavi, S. 2016. Association between objective and subjective assessments of environmental ergonomic factors in manufacturing plants. International Journal of Industrial Ergonomics, 26-31. doi:10.1016/j.ergon.2015.12.004

Erdinc, O., dan Yeow, P.H.P. 2011. Proving External Validity of Ergonomics and Quality Relationship Through Review of Real-World Case Studies,49, 949-962. doi:10.1080/00207540903555502

Giovanni COSTA. 2010. Shift Work and Health: Current Problems and Preventive Actions. Saf Health Work; 1:112-23.

Goetsch, D.L. 2017. Occupational Safety and Health for Technologists, Engineers, and alat bantu penyimpan cairan gleco primer karet; kedua, di stasiun Kerja Pencucian berupa penggunaan APD, dan Stasiun Emboss berupa membuat tombol tambahan.

\section{SARAN}

Agar PE berjalan dengan baik maka diskusi antara pihak manajemen, perwakilan pekerja dan ahli ergonomi dilakukan dengan sungguh-sungguh sampai mendapatkan kesepakatan bersama.

Manager, $8^{\text {th }}$ edition. Pearson Prentice Hall.

Kumar, R., Chaikumarn, M., dan Lundberg, J. 2005. Participatory Ergonomics and an Evaluation of a Low-Cost Improvement Effect on Cleaners' Working Posture. International Journal of Occupational Safety and Ergonomics (JOSE), 11,No.2, 203-210.

Larson, N., Wick, H., Hallbeck, S., dan Vink, P. 2015. Corporate Ergonomics Programs: Identifying Value Through a Company Award Process, 3, 9-23. doi:10.1080/21577323.2014.1001042

Lim SK, Shin HS, Yoon KS, Kwack SJ, Um YM, Hyeon JH, Roh TH. 2014) Risk assessment of volatile organic compounds benzene, toluene, ethylbenzene, and xylene (BTEX) in consumer products. J. Toxicol. Environ. Health, Part A, 2014;77(22-24):1502-21.

Markkanen PK. Occupational Safety and in Indonesia. Manila, Philippines: ILO; 2004. p. 6-8.

Matthews, R. A., Gallus, J. A., \& Henning, R. A. 2011. Participatory Ergonomics : Development of anemployee assesment questionnaire. Accident Analysis and Pervention, 360-369.

Motamedzade, M. 2013. Ergonomics Intervention in an Iranian Tire Manufacturing Industry,19, 475-484. doi:10.1080/10803548.2013.11077003

Nagamachi, M. 199). Requisites and Practice of Participatory Ergonomic. International Journal of Industrial Ergonomics, 15, 371377.

Punett, L., Warren, N., Henning, R., Nobrega, S., \& Cherniak, M. 2013. Participatory Ergonomics as a Model for Integrated 
Programs to Prevent Chronic Disease. Journal of Occupational \& Environmental Medicine, 19-24.

Reason, J. 2000. Human Error: Models and Management. BMJ, 768-770.

Saleem, J.J., Kleiner, B.M., dan Nussbaum, M.A. 2003. Empirical Evaluation of Training and a Work Analysis Tool for Participatory Ergonomics, 31, 387-396. doi:10.1016/S0169-8141(03)00024-6

Santos, I.J.A.L.D., Farias, M.S.,Monteiro, B.G., Falcao, M.A., dan Marcelino, F.D. 2011. Using Participatory Ergonomics to Improve Nuclear Equipment Design, 24, 594-600. doi : 10.10106/j.jlp.2011.04.005

Shah, S.M., dan Silverstein, B.A. 2010. Preparing Employers to Implement the Washington State Ergonomics Rule: Evaluation of The Training Workshops, 1 , 448-455. doi:10.1080/15459620490465820

Skrehot, P., Marek, J., dan Houser, F. (2016). Ergonomics Aspects in Control Rooms, 213. doi:10.1080/1463922X.2016.1159356

Sukapto, P., \& Djojosubroto, H. 2013. Textile industry awareness concerning the implementation of occupational health and safety: a case study of three textile plants in bandung area. Teknologi Indonesia, 8086.

Sukapto, P., \& Djojosubroto, H. 2013. Penerapan Peraturan Pemerintah No. 50 Tahun 2012 Tentang Sistem Manajemen Keselamatan Dan Kesehatan Kerja Untuk Meningkatkan Kinerja Industri Tekstil : Studi Kasus Pada Industri Tekstil Di Bandung. Lembaga Penelitian dan Pengabdian Kepada
Masyarakat Universitas Katolik Parahyangan.

Sukapto, P., Bonita. 2016. Proses, Bahan, dan Energi Ramah Lingkungan: Solusi Berkelanjutan Untuk Menghadapi Perubahan Iklim. Prosiding Simposium Nasional Rekayasa Aplikasi Perancangan dan Industri (RAPI) XV 2016. Halaman : 143-149.

Sundin, A., Christmansson, M., dan Larsson, M. 2004. A Different Perspective in Participatory Ergonomics in Product Development Improves Assembly Work in The Automotive Industry, 33, 1-14. doi:10.1016/j.ergon.2003.06.001

Tompa, E., Dolinschi, R., dan Laing, A. 2009. An Economics Evaluation of a Participatory Ergonomics Process in an Auto Parts Manufacturer, 40, 41-47. doi:10.1016/j.jsr.2008.12.003

Van Eerd D, Cole D, Irvin E, Mahood Q, Keown $\mathrm{K}$, Theberge N, Village J, St. Vincent M, Cullen K. 2010. Process and implementation of participatory ergonomic interventions: a systematic review. Ergonomics, 53(10):1153-66.

Wang, Lingyan dan Lau, Henry Y.K. (2012). Participatory Ergonomics for Psychological Factors Evaluation in Work System Design, Work,41, 2866-2871. DOI:10.3233/WOR-2012-0658-2866.

Wilkinson, C. R., \& Angelli, A. d. 2014. Applying user centred and participatory design approaches to commercial product development. Design Studies, 614-631. 